\title{
Optimization of electroless plating of gold during MACE for through etching of silicon wafer
}

\author{
Muni Raj Maurya ${ }^{a, c}$, Vijaykumar Toutam ${ }^{\text {a,*, }}$ Preetam Singh ${ }^{\mathrm{a}}$, Sivaiah Bathula ${ }^{\mathrm{b}}$ \\ ${ }^{a}$ CSIR-National Physical Laboratory, Dr. K. S. Krishnan Marg, New Delhi, 110012, India \\ ${ }^{\mathrm{b}}$ Advanced Materials and Devices Metrology Division, CSIR-National Physical Laboratory, Dr. K. S. Krishnan Marg, New Delhi, 110012, India \\ ${ }^{c}$ Academy of Scientific and Innovative Research (AcSIR), CSIR-National Physical Laboratory, Dr. K. S. Krishnan Marg, New Delhi, 110012, India
}

\section{A R T I C L E I N F O}

\section{Keywords:}

Metal assisted chemical etching

Gold

Electroless plating

Silicon

Through etching

\begin{abstract}
A B S T R A C T
Deep etching of silicon (Si) is very much desirable for wide variety of applications. Under the context, a cost effective and reproducible through etching of $\sim 375 \mu \mathrm{m}$ thick $\mathrm{Si}$ wafer is demonstrated through long hour metal assisted chemical etching (MACE) followed by short duration $\mathrm{KOH}$ etching. During MACE, apart from $\mathrm{pH}$ and temperature, metal catalyst size and coverage density during electroless plating plays an important role. Optimization of gold deposition in terms of plating solution concentration and deposition time during MACE is studied for effective through etching. $\mathrm{HAuCl}_{4}$ concentration of $\sim 5 \mathrm{mM}$ for $30 \mathrm{~s}$ is found to be best suited for MACE and produces deep and highly dense pores in Si with threshold pore radius $\sim 250 \mathrm{~nm}$ and above. Following the MACE, KOH etching effectively scoops out porous Si to realize through etching.
\end{abstract}

\section{Introduction}

Silicon (Si) micromachining is extensively used for the fabrication of patterns and complex three dimensional structures. Introduction of new techniques like surface micromachining [1], anisotropic etching [2], LIGA process [3] and Bosch process [4] has revolutionized its application in microfluidics [5] and micro-electro-mechanical systems (MEMS) devices [6] etc. Deep etching of Si by dry and wet anisotropic etching requires a hard mask of $\mathrm{Si}_{3} \mathrm{~N}_{4} / \mathrm{SiO}_{2}$. Many of the techniques and the processes like low pressure chemical vapor deposition (LPCVD), plasma-enhanced chemical vapor deposition (PECVD) and thermal oxidation are carried out in controlled environment where pressure, flow rate of gases, temperature etc needs to be maintained for high quality growth of $\mathrm{Si}_{3} \mathrm{~N}_{4} / \mathrm{SiO}_{2}$ [7]. Considering these many variable parameters in the growth process and the maintenance of instrument increases the cost of production. Thus, a simple wet etch techniques using polymer as a mask will be viable and useful for many researchers to practice without the need of such high end facilities. Silicon anisotropic wet etching is done in hydroxide containing solution, where crystal planes with different hybridised $\mathrm{SP}^{3}$ orbital effects the etch rate drastically [8]. Isotropic wet etching of $\mathrm{Si}$ in HF solution is well known which happens in the presence of holes $\left(\mathrm{h}^{+}\right)$, produced by oxidative chemical reaction or supplied externally under bias [9]. Etch profile can be restricted to certain region by trapping hole concentration in selected geometry. HF based metal assisted chemical etching (MACE) method was reported by Li and Bohn [10]. Metals like gold (Au), silver, platinum and copper are patterned on $\mathrm{Si}$ in the desired region of etching [11]. Due to catalytic activity of metal, concentration of holes in the metal vicinity is more, which intern increases $\mathrm{Si}$ rate of etching in these regions. MACE has received much attention in recent years due to its low cost and control over etched morphology. Chartier et al. used molar concentration ratio $(\rho)=[\mathrm{HF}] /\left([\mathrm{HF}]+\left[\mathrm{H}_{2} \mathrm{O}_{2}\right]\right)$ to characterize different etched morphologies [12]. Effect of catalyst shape and concentration, on etched direction was studied by Hildreth et al. [13]. Controlled 3D motion of insulator pinned metal catalyst was also demonstrated by Hildreth et al. [14]. Silicon micromachining using MACE produces, porous $\mathrm{Si}, \mathrm{Si}$ nanowires, patterned structure and have application in trench capacitor, antireflective surface, thermal conversion, and bio-mimic super-hydrophobicity etc $[15,16]$.

Deep etching of Si by wet method requires hard mask or metal as catalyst. Fabrication of through wafer micro funnel has been reported previously [17]. Dry etching in combination with anisotropic $\mathrm{KOH}$ etching is adopted for realization of high density devices and interconnects in packaging. Recently, MACE based deep etching of Si is reported, where metal is deposited by evaporation or sputtering technique [18]. Implementation of these processes in large-scale manufacturing increase the production cost. Thus, a simpler and a cost effective method entirely based on wet synthesis is required for deep or through etching of Si wafer, resulting in large scale production of devices.

\footnotetext{
* Corresponding author.

E-mail address: toutamvk@nplindia.org (V. Toutam).
} 
In the present work we report through etching of Si wafer using electroless plated Au as catalyst and polymer as mask. Long hour MACE is adopted to make deep and high density pores in $\mathrm{Si}$, followed by short duration $\mathrm{KOH}$ etching to scoop out porous $\mathrm{Si}$ and reveal effective etch depth. Gold electroless plating concentration and deposition time is optimized to get highly porous $\mathrm{Si}$ during MACE having threshold pore radius and good coverage. The fabricated through hole in Si wafer can be used as window in analysis of optical detector with out of plane contacts [19], through wafer interconnects and is best suited for high density device fabrication.

\section{Experiment}

Boron doped P-type Si wafer $<100>$ with resistivity $1-10 \Omega$-cm and thickness $\sim 375 \mu \mathrm{m}$ were used in experiments. Polished side of the wafer has $\mathrm{SiO}_{2}$ layer of thickness $\sim 200 \mathrm{~nm}$. The wafer was cut in to $10 \times 10 \mathrm{~mm}^{2}$ pieces. Samples were cleaned by sonicating in acetone for 10 min followed by degreasing in ethanol and finally washing with IP and DI water. Samples were functionalized for hydrogen terminated surface by immersing in DI water: HF (100:1 v/v) solution for $1 \mathrm{~min}$. Prebaking of samples were done at $110^{\circ} \mathrm{C}$ for $2 \mathrm{~min}$. PMMA (MW 996,000 ) solution of $0.35 \mathrm{mM}$ in $\mathrm{CHCl}_{3}$ is used for spin coating at $3000 \mathrm{rpm}$ for $90 \mathrm{~s}$ and samples were baked at $90^{\circ} \mathrm{C}$ for $60 \mathrm{~min}$ in an oven. A window of size $1 \times 4 \mathrm{~mm}^{2}$ was created in PMMA through exposure technique and $\mathrm{SiO}_{2}$ in the exposed region was etched using $\mathrm{HF}$ solution. Electroless plating of $\mathrm{Au}$ was done in the open window of $\mathrm{Si}$ surface for different duration of $5,10,20,30 \mathrm{~s}$, and for different concentrations of $0.1,1,5$ and $10 \mathrm{mM}$ of $\mathrm{HAuCl}_{4} \cdot 3 \mathrm{H}_{2} \mathrm{O}$ in $5 \mathrm{M} \mathrm{HF}$. For easy understanding, all samples treated for Au deposition in various $\mathrm{Au}$ salt concentrations are denoted as sample A, B, C and D for 0.1, 1, 5 and $10 \mathrm{mM}$, respectively and sample $(\mathrm{x}, \mathrm{y})$ notation is used, where y stands for deposition time of 5, 10, 20 and $30 \mathrm{~s}$. For etch rate dependence and etch depth analysis based on Au coverage, MACE of all samples was done for $5 \mathrm{~h}$ in a solution of $2.6 \mathrm{M} \mathrm{HF}$ and $8.1 \mathrm{M} \mathrm{H}_{2} \mathrm{O}_{2}$ having molar concentration ratio $(\rho) \sim 0.24$, followed by $\mathrm{KOH}$ etching in $30 \mathrm{wt} \%$ of solution at $60{ }^{\circ} \mathrm{C}$ for $15 \mathrm{~min}$. For through etching of $\mathrm{Si}$ wafer, a $30 \mathrm{~h}$ prolonged MACE was done followed by $\mathrm{KOH}$ etching for $15 \mathrm{~min}$.

Field emission scanning electron microscope (Zeiss) was used for the morphological observations of the samples. Stylus profiler (AMBIOS $\mathrm{XP}-200$ ) is used to analyse the etch depth of samples.

\section{Results and discussion}

Fig. 1 shows SEM image of Au deposited on Si by electroless plating for $30 \mathrm{~s}$ in various concentration of $0.1,1,5 \& 10 \mathrm{mM}$ Au precursor. For sample (A, 30), clusters of Au nanoparticles with very low coverage density are formed, as shown in Fig. 1a. The inset of the figure shows initial growth of nanoparticle and seed growth during the cluster formation. With increase in metal precursor concentration for sample (B, 30), agglomeration of clusters takes place forming $\mathrm{Au}$ islands, and metal coverage density on substrate increases. The inset of sample (B, 30) shows the growth of highly porous interconnecting network, tending to form film. For sample (C, 30) and sample (D, 30), formation of $\mathrm{Au}$ film is observed. Inset of respective figures shows that the film formed in sample $(\mathrm{C}, 30)$ is more porous with wider cracks as compared to film formed in sample (D, 30).

Fig. 2 shows SEM image of porous $\mathrm{Si}$ wafer after $5 \mathrm{~h}$ MACE for $\mathrm{Au}$ plated Si under various molar concentrations and deposition time of $30 \mathrm{~s}$, along with pore radius distribution. Centre figure summarizes the behaviour of mean pore radius and density of pores for the threshold radius ( $\mathrm{r}$ ) $\sim 250 \mathrm{~nm}$ and above. For sample (A, 30), MACE produces corrugated Si surface with pores having mean radius $\sim 140 \mathrm{~nm}$, as shown in Fig. 2a. With increase in Au plating concentration, for sample (B, 30) size of deposited Au clusters increases forming a network and increase in coverage density (see Fig. 1b). As a result, wider pores are formed with mean pore radius $\sim 200 \mathrm{~nm}$, as shown in Fig. 2b. Similar trend is observed for sample (C, 30). Complete Si surface is covered with bigger clusters during electroless plating forming a porous film (see Fig. 1c). MACE of sample (C, 30) leads to almost regular size pores with mean pore radius $\sim 250 \mathrm{~nm}$ and good coverage density, as shown in Fig. 2c. With further increase in Au plating concentration, for sample (D, 30), shallow etch pits are formed with very few and wide deep pores. Radius distribution of shallow etch pits is shown in the inset of Fig. $2 \mathrm{~d}$ and has a peak at $\sim 400 \mathrm{~nm}$. For compact and thicker Au films, etch rate during MACE decreases as the chemical species have to diffuse over large distance [20]. As a result, uniform etching with shallow etch pits form compared to porous and deep etching observed for porous metal films. For porous Au film with increase in cluster size, pore size, etch depth increases due to enhanced transport of chemical species and redox reaction within the pore [21]. Even though SEM image won't give quantitative information about the depth of the pores, from the contrast of the pores it can be emphasized qualitatively that the depth of the pores is maximum for sample (C, 30). Thus, pores having threshold pore radius $\sim 250 \mathrm{~nm}$ and above with high coverage density contributes to highly porous structure and are suitable for through etching of Si wafer. Centre plot in Fig. 2 summarizes the mean pore radius and density of pores with threshold radius $\sim 250 \mathrm{~nm}$ and above for different Au plated $\mathrm{Si}$ wafers. Left $y$-axis of the plot shows the variation of mean pore radius with increase in Au plating concentration. Clearly as the plating concentration increase the mean pore radius increases due to increase in particle size of catalyst. Right y-axis shows the variation of pore density with Au plating concentration for threshold pore radius $\sim 250 \mathrm{~nm}$ and above. From the plot it is observed that sample (C, 30) has highest pore density above threshold pore radius, and is best suited for through etching of Si wafer.

Fig. 3 shows change in morphology of single MACE etch pore after short duration of $\mathrm{KOH}$ etching and their evolution by merging with adjacent pores forming a larger pore. MACE of sample $(\mathrm{C}, 30)$ leads to formation of pores above threshold radius. The short $\mathrm{KOH}$ treatment widens the pore and will terminates at $<111>$ facet making an angle $\sim 54.7^{\circ}$ with $<100>$ plane [7]. The lateral widening $\left(l_{\text {shift }}\right)$ of the pore by $\mathrm{KOH}$ etching for time (t) min can be calculated using the formula given in Fig. 3a. The etch rates of the $\mathrm{Si}<111>$ plane $\left(\mathrm{R}_{<111>}\right)$ in $30 \mathrm{wt} \% \mathrm{KOH}$ at $70{ }^{\circ} \mathrm{C}$ is $\sim 5 \mathrm{~nm} / \mathrm{min}$ [22]. For $15 \mathrm{~min}$ of $\mathrm{KOH}$ etching the calculated lateral shift is $\sim 90 \mathrm{~nm}$. For MACE etched pores having inter-pore distance $\sim 180 \mathrm{~nm}$, pore walls collapse after KOH treatment and they merge to form a bigger pore, as shown in Fig. 3b. Pores formed after $\mathrm{KOH}$ etching has straight edges due to anisotropic etching of Si.

Fig. 4 shows SEM image of sample (C, 30) after $5 \mathrm{~h}$ MACE followed by $10-15$ min KOH etching along with stylus plot. Fig. 4a shows SEM image of sample (C, 30) after $5 \mathrm{~h}$ MACE with two contrast regions of 10 and $15 \mathrm{~min} \mathrm{KOH}$ etching. From Fig. 4a, it is observed that the left half of the sample surface after $10 \mathrm{~min} \mathrm{KOH}$ etching retains the porous structure of $\mathrm{Si}$. Whereas, the right half of the sample after $15 \mathrm{~min} \mathrm{KOH}$ treatment leaves a flat Si surface, scooping out the whole porous structure and the effective MACE etch depth is exposed. Fig. 4b shows cross sectional SEM image of sample (C, 30) after $5 \mathrm{~h}$ MACE and $10 \mathrm{~min}$ $\mathrm{KOH}$ etching. A gradient in the etch profile is observed with maximum etch depth at the centre of the etched window. This is due to non uniform deposition of the $\mathrm{Au}$ at the edge of the window covered with polymer, resulting in non uniform etch depth during MACE. At the centre region of the window where Au plating is uniform, maximum etch depth $\sim 60 \mu \mathrm{m}$ is observed. The leftover Si morphology seen in the etched window is due to $10 \mathrm{~min} \mathrm{KOH}$ etching and can be removed after extended $5 \mathrm{~min} \mathrm{KOH}$ etching. The magnified SEM image of the Si morphology at the centre of etched window after $5 \mathrm{~h}$ MACE and $10 \mathrm{~min}$ of $\mathrm{KOH}$ etching is shown in Fig. 4c. Silicon pillars of $\sim 10 \mu \mathrm{m}$ length are observed. Silicon pillars are mostly round in shape with tapered top, resulting in formation of cones, as shown in the inset Fig. 4c. The evolution of cone shape morphology is attributed to the anisotropic etching property of the KOH. Fig. 4d shows line profile analysis of etch depth after $5 \mathrm{~h}$ MACE followed by $10 \mathrm{~min} \mathrm{KOH}$ etching of sample (C, 


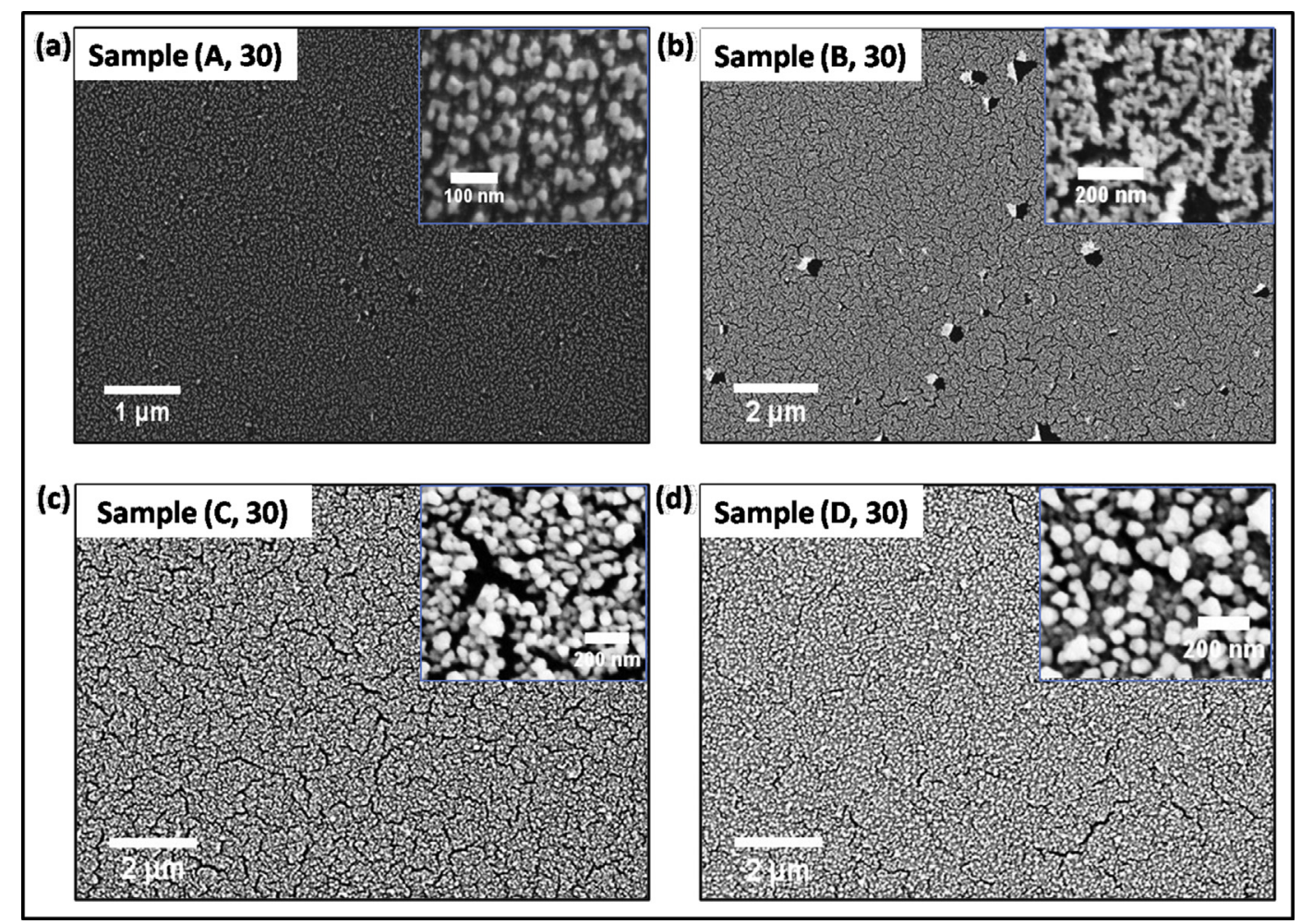

Fig. 1. SEM images of electroless plated Au on Si substrate for $30 \mathrm{~s}$ deposition time in various molar concentration of (a) $0.1 \mathrm{mM}$. (b) $1 \mathrm{mM}$. (c) $5 \mathrm{mM}$. (d) $10 \mathrm{mM}$, respectively.

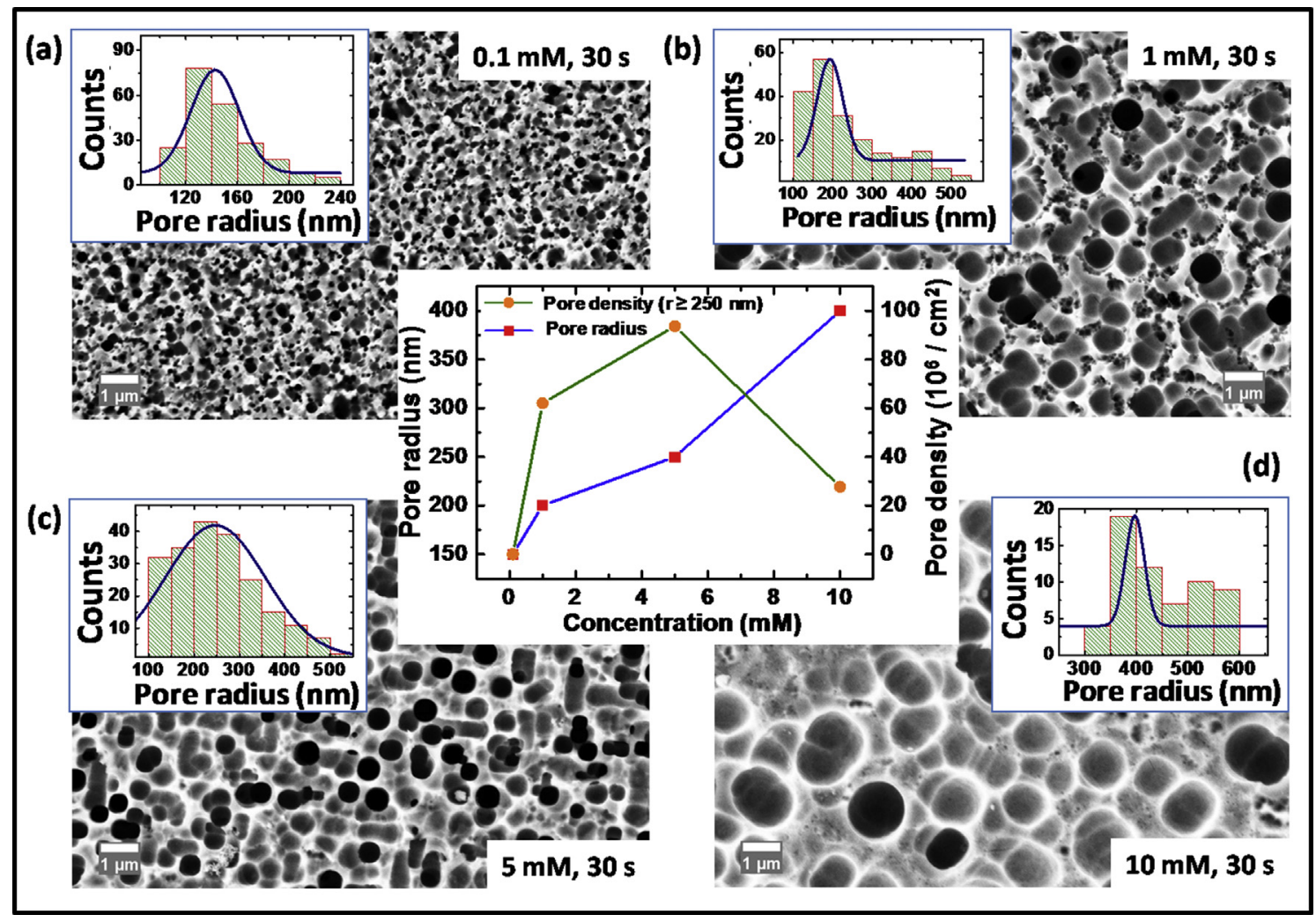

Fig. 2. SEM images of Si wafer after $5 \mathrm{~h}$ MACE, using $30 \mathrm{~s}$ electroless plated Au in various molar concentrations as catalyst, along with pore radius distribution in the inset. (a) Sample (A, 30). (b) Sample (B, 30). (c) Sample (C, 30). (d) Sample (D, 30). Centre figure shows mean pore radius and density of pores with threshold radius (r) $\sim 250 \mathrm{~nm}$ and above, for Au plated Si in different concentrations and deposition time of $30 \mathrm{~s}$ after $5 \mathrm{~h}$ MACE. 
(a)

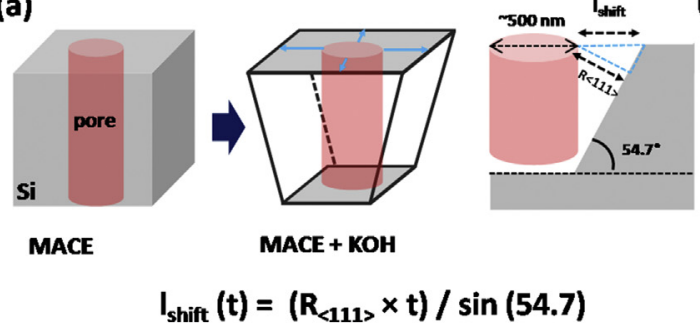

(b)

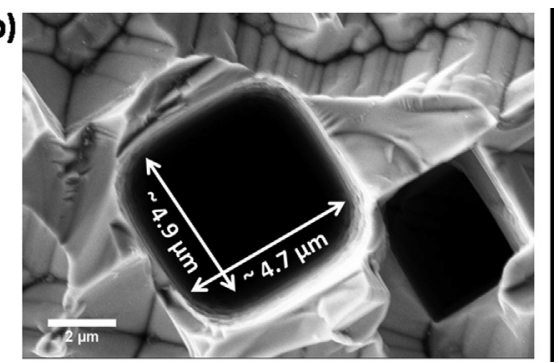

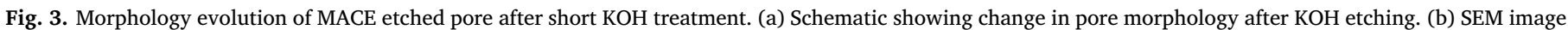
of the pore having almost square periphery after short duration of $\mathrm{KOH}$ treatment.

30). A U-shaped etch profile with vertical depth of $54 \pm 3 \mu \mathrm{m}$ having slant edges is observed, as shown in Fig. 4d. The fluctuation in the height at the base of the etched pit is due to presence of Si pillars after $10 \mathrm{~min} \mathrm{KOH}$ etching.

Fig. 5 shows etch depth analysis after $5 \mathrm{~h}$ MACE followed by $15 \mathrm{~min}$ $\mathrm{KOH}$ etching of $\mathrm{Au}$ plated $\mathrm{Si}$ in various molar concentration and deposition time along with array of through holes in Si. For sample A, etch depth of less than $\sim 5 \mu \mathrm{m}$ and no dependence on Au deposition time is observed, as shown in Fig. 5a (red curve). In sample A, isolated clusters of gold are deposited for various electroless plating time. MACE of these samples leads to formation of widely separated pores in the Si. Thus, $\mathrm{KOH}$ etching only widens the pores and leads to facet termination. As a result, effective MACE etch depth is not exposed. Fig. 5a (black curve) shows the etch depth of sample B for various deposition time. For sample (B, 5), clusters of Au nanoparticles are deposited and the density of these clusters increases in sample (B, 10). The MACE $+\mathrm{KOH}$ etch depths of sample (B, 5) and (B, 10) are almost similar up to $17 \pm 2 \mu \mathrm{m}$. With increase in deposition time for sample (B, 20) and sample (B, 30), interconnected islands of Au are deposited on the Si surface. As a result, pore radius and coverage area increases during MACE. Thus, surface exposed for $\mathrm{KOH}$ etching is more and it scoops out porous $\mathrm{Si}$ to reveal effective MACE etch depth of $43 \pm 3 \mu \mathrm{m}$. For sample C, irrespective of deposition time porous Au film is deposited on the Si substrate. With further increase in aggregation of Au in sample (C, 30), MACE etch depth increases and leads to high density of wide pores. As a result, KOH scoops out porous Si morphology and actual MACE etch depth of $54 \pm 3 \mu \mathrm{m}$ is exposed, as shown in Fig. 5a (cyan curve). Compared to etch depth of sample C, for sample D there is no dependence of etch depth on Au deposition time and fluctuates about mean etch depth of $45 \pm 11 \mu \mathrm{m}$, as shown in Fig. 5 a (blue curve). As the concentration of Au salt increases beyond $5 \mathrm{mM}$, compactness of the Au film increases and MACE etching is more at the edges due to ease in mass transfer. Due to imbalance in spatial etching, cracks are induced in the film leading to fluctuating etch rate and won't show any systematic dependence on $\mathrm{Au}$ plating time. Thus, gold deposition in molar concentration $\sim 5 \mathrm{mM}$ and deposition time $\sim 30 \mathrm{~s}$ is best suited for through etching of $\mathrm{Si}$ wafer. Fig. $5 \mathrm{~b}$ shows array of through holes in $\sim 375 \mu \mathrm{m}$ thick Si wafer by long hour MACE followed by short KOH etching. Array of $3 \times 3$ window on Si with area of $1 \times 1 \mathrm{~mm}^{2}$ were fabricated using exposure technique with PMMA as protective layer and Au was deposited in $5 \mathrm{mM}$ Au salt solution for $30 \mathrm{~s}$. MACE of $30 \mathrm{~h}$ followed by $15 \mathrm{~min} \mathrm{KOH}$ etching results in formation of array of through holes in $\sim 375 \mu \mathrm{m}$ thick Si wafer as shown in Fig. 5b. Non-uniformity in the shape of through etched holes can be overcome by having abrupt polymer edges in the etched window. The proposed deep etching of Si can be used in through wafer interconnects for high density device fabrication and as window in (a)

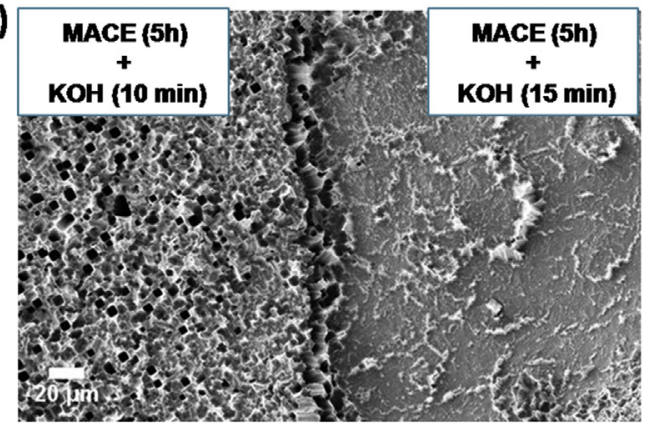

(c)

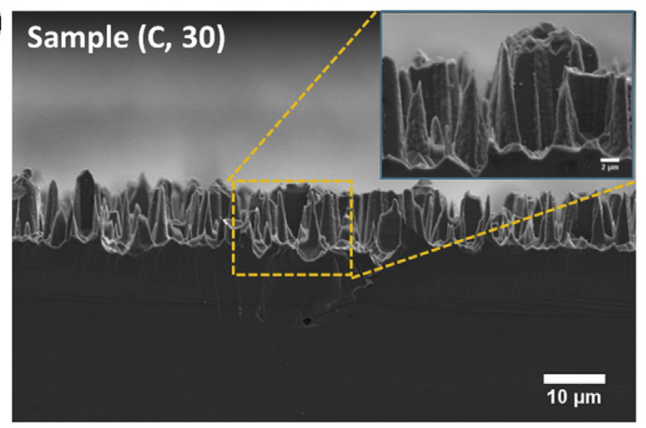

(b)

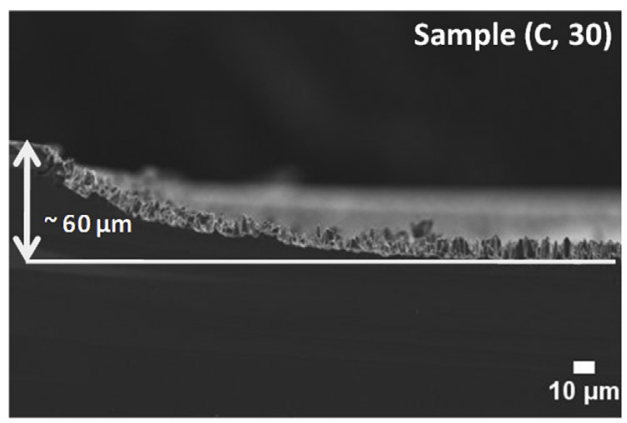

(d)

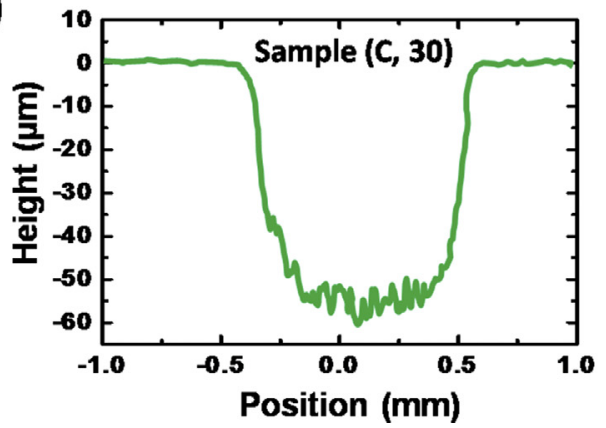

Fig. 4. SEM images of sample (C, 30) after $5 \mathrm{~h}$ MACE followed by short KOH etching along with stylus plot. (a) SEM image after 10, 15 min KOH etching. (b, c) Cross sectional, zoomed in SEM image after $10 \mathrm{~min} \mathrm{KOH}$ etching, respectively. (d) Line profile analysis of etch depth after $5 \mathrm{~h}$ MACE and $10 \mathrm{~min}$ KOH etching. 


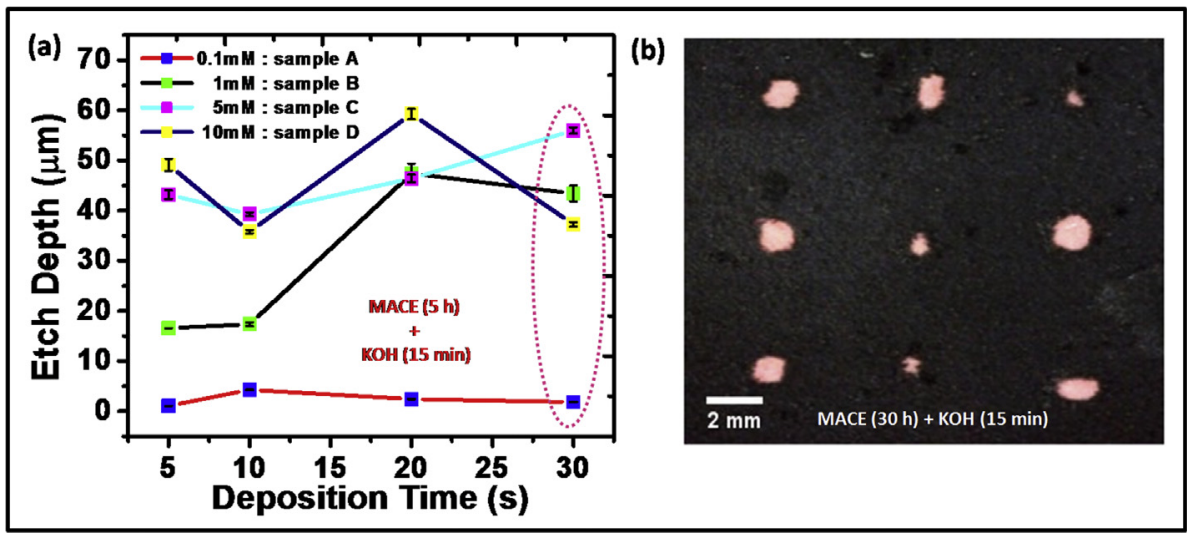

Fig. 5. MACE $+\mathrm{KOH}$ etch depth analysis using stylus profiler for Au plating in various molar concentration and deposition time, along with array of through holes in Si wafer. (a) Etch depth analysis after $5 \mathrm{~h}$ MACE followed by $15 \mathrm{~min} \mathrm{KOH}$ etching. (b) Array of $3 \times 3$ through holes in $\sim 375 \mu \mathrm{m}$ thick Si wafer after $30 \mathrm{~h}$ MACE using $5 \mathrm{mM}$ and $30 \mathrm{~s}$ electroless plated $\mathrm{Au}$ as catalyst followed by $15 \mathrm{~min}$ of $\mathrm{KOH}$ etching. analysis of optical detector with out of plane contacts [19]. Further, the work is focused on the effect of temperature and inclusion of more electronegative metal like silver to enhance the MACE rate of etching.

\section{Conclusion}

Deep etching of Si wafer is studied with combination of MACE and $\mathrm{KOH}$ etching. Electroless plating of $\mathrm{Au}$ in various molar concentrations is adopted for MACE etching of Si wafer. Etch depth is analysed in terms of metal coverage density using stylus profiler. High metal coverage density, results in formation of deep, wide and high density pores in Si wafer. Gold deposition in molar concentration $\sim 5 \mathrm{mM}$ and deposition time $\sim 30 \mathrm{~s}$ is best suited for through etching of $\mathrm{Si}$ wafer.

\section{Acknowledgements}

Mr. Muni Raj acknowledges Council of Scientific and Industrial Research (CSIR) \& Academy of Scientific and Innovative Research (AcSIR) for fellowship and academic support. Dr. Toutam acknowledges DST-SERB for their financial support under FTYS project (GAP -161232).

\section{References}

[1] J.M. Bustillo, R.T. Howe, R.S. Muller, Surface micromachining for microelectromechanical systems, Proc. IEEE 86 (1998) 1552-1574 https://ieeexplore.ieee.org/ abstract/document/704260.

[2] K.E. Bean, Anisotropic etching of silicon, IEEE Trans. Electron Devices 25 (1978) 1185-1193 https://ieeexplore.iee.org/stamp/stamp.jsp?tp = \&arnumber $=$ $1479644 \& \operatorname{tag}=1$.

[3] E.W. Becker, W. Ehrfeld, P. Hagmann, A. Maner, D. Münchmeyer, Fabrication of microstructures with high aspect ratios and great structural heights by synchrotron radiation lithography, galvanoforming, and plastic moulding (LIGA process), Microelectron. Eng. 4 (1986) 35-56 https://doi.org/10.1016/0167-9317(86) 90004-3.

[4] F. Laermer, A. Schilp, Method of anisotropically etching silicon, U. S. Patent No. 5501893 (3, 26, 1996). https://patentimages.storage.googleapis.com/69/2d/c4/ af6ae016bc71da/US5501893.pdf.

[5] M.J.D. Boer, R.W. Tjerkstra, J.W. Berenschot, H.V. Jansen, G.J. Burger, J.G.E. Gardeniers, M. Elwenspoek, A.V.D. Berg, Micromachining of buried micro channels in silicon, J. Microelectromech. Syst. 9 (2000) 94-103 https://ieeexplore. ieee.org/document/825783.

[6] J.W. Judy, Microelectro-mechanical systems (MEMS): fabrication, design and applications, Smart Mater. Struct. 10 (2001) 1115-1134 https://doi.org/10.1088/ 0964-1726/10/6/301.
[7] G.T.A. Kovacs, N.I. Maluf, K.E. Petersen, Bulk micromachining of silicon, Proc. IEEE 86 (1998) 1536-1551 https://ieeexplore.ieee.org/document/704259.

[8] W. Lang, Silicon microstructuring technology, Mater. Sci. Eng. R Rep. 17 (1996) 1-55 https://doi.org/10.1016/0927-796X(96)00190-8.

[9] V. Lehmann, H. Föll, Formation mechanism and properties of electrochemically etched trenches in n-type silicon, J. Electrochem. Soc. 137 (1990) 653-659 http:// jes.ecsdl.org/content/137/2/653.

[10] X. Li, P.W. Bohn, Metal-assisted chemical etching in $\mathrm{HF} / \mathrm{H}_{2} \mathrm{O}_{2}$ produces porous silicon, Appl. Phys. Lett. 77 (2000) 2572-2574 https://aip.scitation.org/doi/10. 1063/1.1319191.

[11] T. Fatima, B.M. Jeffrey, M.D. Lauren, N. Logan, D. Wenqi, P.J. Michael, Y. Joanne, F. Joanne, R.B. Marcie, Nanostructured silicon via metal assisted catalyzed etch (MaCE): chemistry fundamentals and pattern engineering, Nanotechnology 27 (2016) 412003 https://doi.org/10.1088/0957-4484/27/41/412003.

[12] C. Chartier, S. Bastide, C. Lévy-Clément, Metal-assisted chemical etching of silicon in $\mathrm{HF}-\mathrm{H}_{2} \mathrm{O}_{2}$, Electrochim. Acta 53 (2008) 5509-5516 https://doi.org/10.1016/j. electacta.2008.03.009.

[13] O.J. Hildreth, W. Lin, C.P. Wong, Effect of catalyst shape and etchant composition on etching direction in metal-assisted chemical etching of silicon to fabricate $3 \mathrm{D}$ nanostructures, ACS Nano 3 (2009) 4033-4042 https://pubs.acs.org/doi/abs/10 1021/nn901174e.

[14] O.J. Hildreth, D. Brown, C.P. Wong, 3D out-of-Plane rotational etching with pinned catalysts in metal-assisted chemical etching of silicon, Adv. Funct. Mater. 21 (2011) 3119-3128 https://doi.org/10.1002/adfm.201100279.

[15] H. Han, Z. Huang, W. Lee, Metal-assisted chemical etching of silicon and nanotechnology applications, Nano Today 9 (2014) 271-304 https://doi.org/10.1016/j. nantod.2014.04.013.

[16] Y. Xiu, L. Zhu, D.W. Hess, C.P. Wong, Hierarchical silicon etched structures for controlled hydrophobicity/superhydrophobicity, Nano Lett. 7 (2007) 3388-3393 https://pubs.acs.org/doi/10.1021/n10717457.

[17] J.M. Archer, S.F. Ligler, Fabrication and characterization of silicon micro-funnels and tapered micro-channels for stochastic sensing applications, Sensors 8 (2008) 3848-3872 https://doi.org/10.3390/s8063848.

[18] B. Miao, J. Zhang, X. Ding, D. Wu, Y. Wu, W. Lu, J. Li, Improved metal assisted chemical etching method for uniform, vertical and deep silicon structure, J. Micromech. Microeng. 27 (2017) 055019https://doi.org/10.1088/1361-6439/ aa6872.

[19] M.R. Maurya, V. Toutam, Fast response UV detection based on waveguide characteristics of vertically grown $\mathrm{ZnO}$ nanorods partially embedded in anodic alumina template, Nanotechnology 30 (2018) 085704 https://doi.org/10.1088/1361-6528/ aaf545.

[20] H.D. Um, N. Kim, K. Lee, I. Hwang, J. Hoon Seo, Y.J. Yu, P. Duane, M. Wober, K. Seo, Versatile control of metal-assisted chemical etching for vertical silicon microwire arrays and their photovoltaic applications, Sci. Rep. 5 (2015) 11277 https://doi.org/10.1038/srep11277.

[21] C.L. Lee, K. Tsujino, Y. Kanda, S. Ikeda, M. Matsumura, Pore formation in silicon by wet etching using micrometre-sized metal particles as catalysts, J. Mater. Chem. 18 (2008) 1015-1020 https://doi.org/10.1039/B715639A.

[22] K. Sato, M. Shikida, Y. Matsushima, T. Yamashiro, K. Asaumi, Y. Iriye, M. Yamamoto, Characterization of orientation-dependent etching properties of single-crystal silicon: effects of $\mathrm{KOH}$ concentration, Sens. Actuators, A-Phys. 64 (1998) 87-93 https://doi.org/10.1016/S0924-4247(97)01658-0. 